\title{
Common Agency and Coordination: General Theory and Application to Government Policy Making
}

\section{Citation}

Dixit, Avinash, Gene M. Grossman, and Elhanan Helpman. 1997. Common agency and coordination: General theory and application to government policy making. Journal of Political Economy 105(4): 752-769.

\section{Published Version}

doi:10.1086/262092

\section{Permanent link}

http://nrs.harvard.edu/urn-3:HUL.InstRepos:3450061

\section{Terms of Use}

This article was downloaded from Harvard University's DASH repository, and is made available under the terms and conditions applicable to Other Posted Material, as set forth at http:// nrs.harvard.edu/urn-3:HUL.InstRepos:dash.current.terms-of-use\#LAA

\section{Share Your Story}

The Harvard community has made this article openly available.

Please share how this access benefits you. Submit a story.

\section{Accessibility}




\title{
Common Agency and Coordination: General Theory and Application to Government Policy Making
}

\author{
Avinash Dixit and Gene M. Grossman \\ Princeton University \\ Elhanan Helpman \\ Tel Aviv University and Canadian Institute for Advanced Research
}

\begin{abstract}
We develop a model of common agency with complete information and general preferences with nontransferable utility, and we prove that the principals' Nash equilibrium in truthful strategies implements an efficient action. We apply this theory to the construction of a positive model of public finance, where organized special interests can lobby the government for consumer and producer taxes or subsidies and targeted lump-sum taxes or transfers. The lobbies use only the nondistorting transfers in their noncooperative equilibrium, but their intergroup competition for transfers turns into a prisoners' dilemma in which the government captures all the gain that is potentially available to the parties.
\end{abstract}

\section{Introduction}

Common agency is a multilateral relationship in which several principals simultaneously try to influence the actions of an agent. Such situations occur frequently, particularly in the political processes

We thank Timothy Besley, Stephen Coate, Chaim Fershtman, Giovanni Maggi, David Pines, and a referee for their comments on earlier versions of this paper and the National Science Foundation and the Israel-U.S. Binational Science Foundation for financial support. 
that generate economic policies. For example, legislators respond to many diverse pressures, including those from voters, contributors, and party officials. Administrative agencies, formally responsible to the lawmakers, are in practice influenced by the courts, the media, and various interest and advocacy groups. In the European Union, several sovereign governments deal with a common policy-making body in Brussels. And in the United States, the devolution of economic power to the states and localities may give governments at these levels the standing of principals in relation to the federal government.

Information asymmetries are important in a common agency just as in an agency with a single principal. However, even with complete information, the existence of multiple principals introduces the new issues of whether they can achieve an outcome that is efficient for the group of players (the principals and the agent together) and how the available surplus gets divided among players. Bernheim and Whinston (1986) show that a noncooperative menu auction among the principals does have an efficient equilibrium. Their model has found many applications, including the study of lobbying for tariffs (Grossman and Helpman 1994) and for consumer and producer taxes and subsidies (Dixit 1996).

However, the Bernheim-Whinston model assumes quasi-linear preferences, so monetary transfers are equivalent to transferable utility among the principals and their common agent. This is usual and acceptable in the partial equilibrium analysis of industrial organization for which the Bernheim-Whinston model was originally designed, but it is generally inappropriate in most other economic settings, which require a more general equilibrium analysis. In models of economic policy, whether normative or positive, the most important drawback of quasi linearity is that it gives incomplete or implausible answers to distributional questions. For example, consider a policy maker who has a Benthamite (additive) social welfare function as part of his objective. Then since quasi linearity implies constant marginal utilities of income, the policy maker can have no concern for distribution per se. In reality, leaders do often care about income inequality. Next, in the common agency framework of recent political economy models, where the politically organized interest groups are the principals and the government is the agent, the government's implied objective is a weighted sum of utilities in which favored or organized groups get a higher weight. Then a government that has access to efficient means of transfer will drive the less favored or unorganized groups down to their minimum subsistence utility levels, whereas distribution among the favored or orga- 
nized groups will be indeterminate; both features are unrealistic. (See Dixit [1996] for further discussion of this.) Finally, quasi linearity makes the agent's actions independent of the distribution of payoffs among the principals. ${ }^{1}$ In short, the assumption of quasi linearity makes the model unsuitable for analyzing distribution and transfer policies that are of the essence in public finance and political economy.

In most economic applications, money is indeed transferable, but the players' payoffs are not linear in money. The strict concavity of utilities in money incomes makes the levels of transfers in the political equilibrium determinate and nonextreme. In this paper we generalize the theory of common agency to handle such situations. We thereby hope to enlarge the scope of applicability of the theory.

We begin by characterizing equilibria for the general common agency problem. We proceed to show that, even when utility is not transferable across players, the agent's actions in equilibrium achieve an efficient outcome for the group of players (principals and agent). Of course, the actions are no longer independent of the distribution of payoffs among the players, and in equilibrium the two sets of magnitudes must be determined simultaneously. ${ }^{2}$

We then consider a political process of economic policy making in the common agency framework. A subset of all individuals are allowed to lobby the government and promise contributions in return for policy favors. The government cares for social welfare defined over the utilities of all individuals (lobbying or not) and for its receipts from the lobbyists. The efficiency theorem then says that the government uses the available policy instruments in a Paretoefficient manner.

To clarify the implications of our analysis, we apply the results to a positive model of the formation of tax policy. Our model is analogous to the familiar normative model of Diamond and Mirrlees (1971). The policy instruments we allow are commodity tax or subsidy policies and individualized lump-sum transfers, and the political process admits lobbying of the sort described above. Here the efficiency result implies that only the nondistorting lump-sum transfers are used in the political equilibrium, not consumption or production taxes or subsidies. However, the game of lobbying for transfers turns into a prisoners' dilemma for the lobbyists. Indeed, under mild

\footnotetext{
${ }^{1}$ Note the parallel with the Coase theorem, where under quasi-linear utility (no income effects on the activities in question), resource allocation is independent of distribution.

${ }^{2}$ The parallel with the Coase theorem or the core with nontransferable utility should again be apparent. However, we should stress that ours is an equilibrium of a noncooperative game, not a cooperative solution concept.
} 
additional assumptions, we find that the government captures all the gains that exist in the common agency relationship. This suggests that if the lobbies could commit ex ante to a "constitution" for lobbying, they would all agree not to lobby for lump-sum transfers. This opens the way for the use of economically inferior instruments such as production subsidies, with an attendant violation of production efficiency in the political equilibrium, contrary to an important general feature of the normative optimum (Diamond and Mirrlees 1971).

\section{General Theory}

Consider the following problem. There is a set $L$ of principals. For each $i \in L$, principal $i$ has continuous preferences $U^{i}\left(\mathbf{a}, c_{i}\right)$, where the vector a denotes the agent's action and the scalar $c_{i}$ denotes principal $i$ 's payment to the agent. Each principal's preference function is declining in his payment to the agent. The agent's continuous preference function is $G(\mathbf{a}, \mathbf{c})$, where $\mathbf{c}$ is the vector of the principals' payments. The function $G$ is increasing in each component of $\mathbf{c}$. Thus, for any given action, each principal dislikes making contributions and the agent likes receiving them; their preferences with regard to actions are not restricted in general, but we shall place some specific restrictions for particular results below. We refer to the values of the functions $U^{i}\left(\mathbf{a}, c_{i}\right)$ and $G(\mathbf{a}, \mathbf{c})$ as the utility levels of the principals and the agent, respectively.

Principal $i$ can choose a payment function $C_{i}(\mathbf{a})$ from a set $\mathscr{C}_{i}$ and the agent can choose a from a set $\mathscr{A}$. The sets $\mathscr{C}_{i}$ and $\mathscr{A}$ describe feasibility and institutional constraints. For example, from feasibility considerations, $\mathscr{C}_{i}$ may consist only of functions that provide principal $i$ with a nonnegative income. Or it may consist only of nonnegative functions, implying that the principal can pay the agent but not the reverse. This would describe an institutional constraint. And it may contain only functions with an upper bound on payments, thereby describing another institutional constraint. Similarly, $\mathscr{A}$ may describe institutional or feasibility constraints on the actions of the agent. If, for example, an element of a equals one plus an ad valorem tax rate, then feasibility requires $\mathscr{A}$ to contain only nonnegative vectors.

Throughout, we maintain the following assumption on the sets of feasible payment functions.

Assumption 1. Let $C_{i} \in \mathscr{C}_{i}$. Then $C_{i}(\mathbf{a}) \geq 0$ for all $\mathbf{a} \in \mathcal{A}$, and every payment function $C_{i}^{*}$ that satisfies (i) $C_{i}^{*}(\mathbf{a}) \geq 0$ for all $\mathbf{a} \in \mathscr{A}$ and (ii) $C_{i}^{*}(\mathbf{a}) \leq C_{i}$ (a) for all $\mathbf{a} \in \mathscr{A}$ also belongs to $\mathscr{C}_{i}$.

Explanation. Payments from the principals to the agent have to 
be nonnegative, and if a payment function is feasible, all "smaller" payment functions are also feasible. This conforms to the requirements of most relevant economic applications.

\section{A. Equilibrium}

Our aim is to construct and study a concept of equilibrium for a two-stage game. In the second stage, the agent chooses an action optimally, given the payment functions of all the principals. In the first stage, each principal chooses a payment schedule, knowing that all the other principals are simultaneously and noncooperatively choosing their own payment schedules, and looking ahead to the response of the agent in the second stage.

We shall denote magnitudes pertaining to an equilibrium by the superscript o. Since the game is noncooperative, we shall have to start with a "candidate" for such an equilibrium and study the consequences of allowing the strategies to deviate from this, one player at a time. For this purpose we establish the following notation: $\mathbf{C}^{\circ}(\mathbf{a})$ will denote the vector of contributions with components $C_{j}^{\circ}(\mathbf{a})$, for all $j \in L ;\left(\left\{C_{j}^{\circ}(\mathbf{a})\right\}_{j \neq i}, c\right)$ will denote the vector in which the $i$ th component is replaced by $c$, and all the other components $j \neq i$ are held fixed at $C_{j}^{\circ}(\mathbf{a})$. Sometimes $c$ itself may be the value of another payment function $C_{i}(\mathbf{a})$ for principal $i$.

We begin by defining the principals' best-response strategies.

Definition 1. A payment function $C_{i}^{\circ} \in \mathscr{C}_{i}$ and an action $\mathbf{a}_{i}^{\circ} \in \mathscr{A}$ are a best response of principal $i$ to the payment functions $\left\{C_{j}^{\circ}\right\}_{j \in L, j \neq i}$ of the other principals if

$$
\mathbf{a}_{i}^{\circ} \in \underset{\mathbf{a} \in \mathscr{A}}{\operatorname{argmax}} G\left[\mathbf{a}, \mathbf{C}^{\circ}(\mathbf{a})\right]
$$

and there does not exist a payment function $C_{i} \in \mathscr{C}_{i}$ and an action $\mathbf{a}_{i} \in \mathscr{A}$ such that (i) $U^{i}\left[\mathbf{a}_{i}, C_{i}\left(\mathbf{a}_{i}\right)\right]>U^{i}\left[\mathbf{a}_{i}^{\circ}, C_{i}^{\circ}\left(\mathbf{a}_{i}^{\circ}\right)\right]$ and (ii) $\mathbf{a}_{i} \in$ $\operatorname{argmax}_{\mathbf{a} \in \mathscr{A}} G\left[\mathbf{a},\left(\left\{C_{j}^{\circ}(\mathbf{a})\right\}_{j \neq i}, C_{i}(\mathbf{a})\right)\right]$.

Explanation. The best-response calculation of principal $i$ holds fixed the simultaneously chosen strategies (payment functions) of all the other principals at their candidate equilibrium positions, but recognizes that in the second stage the agent will optimize with respect to these payment functions along with any deviated function proposed by principal $i$. If principal $i$ cannot find another feasible payment function that yields a better outcome for him, taking into account the agent's anticipated response, then the original candidate payment function $C_{i}^{\circ}$ is a best response for principal $i$ to the candidate functions $C_{j}^{\circ}$ of all the other principals. If the agent's best 
response is nonunique, we allow the principal $i$ to designate an action in the agent's set of best responses.

Next we define equilibrium. This is the standard definition of a subgame perfect Nash equilibrium for this two-stage game; in the case of nonuniqueness mentioned just above, for equilibrium we require that all principals be willing to designate the same action $\mathbf{a}^{\circ}$.

Definition 2. An equilibrium of the common agency problem consists of a vector of feasible payment functions $\mathbf{C}^{\circ}=\left\{C_{i}^{\circ}\right\}_{i \in L}$ and a policy vector $\mathbf{a}^{\circ}$ such that, for every $i \in L$, the payment function $C_{i}^{\circ}$ and action $\mathbf{a}^{\circ}$ are a best response of principal $i$ to the payment functions $\left\{C_{j}^{\circ}\right\}_{j \in L, j \neq i}$ of the other principals.

The following result provides a characterization of an equilibrium.

Proposition 1. A vector of payment functions $\mathbf{C}^{\circ}=\left\{C_{i}^{\circ}\right\}_{i \in L}$ and a policy vector $\mathbf{a}^{\circ}$ constitute an equilibrium if and only if $(a) C_{i}^{\circ} \in$ $\mathscr{C}_{i}$ for all $i \in L ;(b) \mathbf{a}^{\circ}=\operatorname{argmax}_{a \in \mathscr{A}} G\left[\mathbf{a}, \mathbf{C}^{\circ}(\mathbf{a})\right]$; and $(c)$ for every $i \in L$,

$$
\left[\mathbf{a}^{\circ}, C_{i}^{\circ}\left(\mathbf{a}^{\circ}\right)\right] \in \underset{(\mathbf{a}, c)}{\operatorname{argmax}} U^{i}(\mathbf{a}, c)
$$

subject to $\mathbf{a} \in \mathscr{A}, c=C_{i}(\mathbf{a})$ for some $C_{i} \in \mathscr{C}_{i}$, and

$$
G\left(\mathbf{a},\left(\left\{C_{j}^{\circ}(\mathbf{a})\right\}_{j \neq i}, c\right)\right] \geq \sup _{\mathbf{a}^{\prime} \in \mathscr{A}} G\left[\mathbf{a}^{\prime},\left(\left\{C_{j}^{\circ}\left(\mathbf{a}^{\prime}\right)\right\}_{j \neq i}, 0\right)\right] .
$$

Explanation. ${ }^{3}$ Observe that conditions $a$ and $b$ must be satisfied by all payment schedules and actions that are best responses. Requirement $c$ is the key aspect of proposition 1: it focuses on the relationship between the agent and one of the principals and helps determine how the potential gains from this relationship get allocated between them in equilibrium.

Examine the situation from the perspective of principal $i$. He takes as given the strategies of all other principals $j \neq i$ and contemplates his own choice. He must provide the agent at least the level of utility that the agent could get from his outside option, namely by choosing a best response to the payment functions offered by all the other principals when principal $i$ offers nothing. This is what constraint (2) expresses. Subject to this constraint, principal $i$ can propose to the agent an action and a feasible payment that maximizes his own utility. That is the content of equation (1). Then proposition 1 says that such constrained maximization by each principal is equivalent to equilibrium as previously defined.

\footnotetext{
${ }^{3}$ To conserve space, we provide here only verbal and intuitive explanations of the propositions; more formal proofs are in our working paper (Dixit, Grossman, and Helpman 1996).
} 


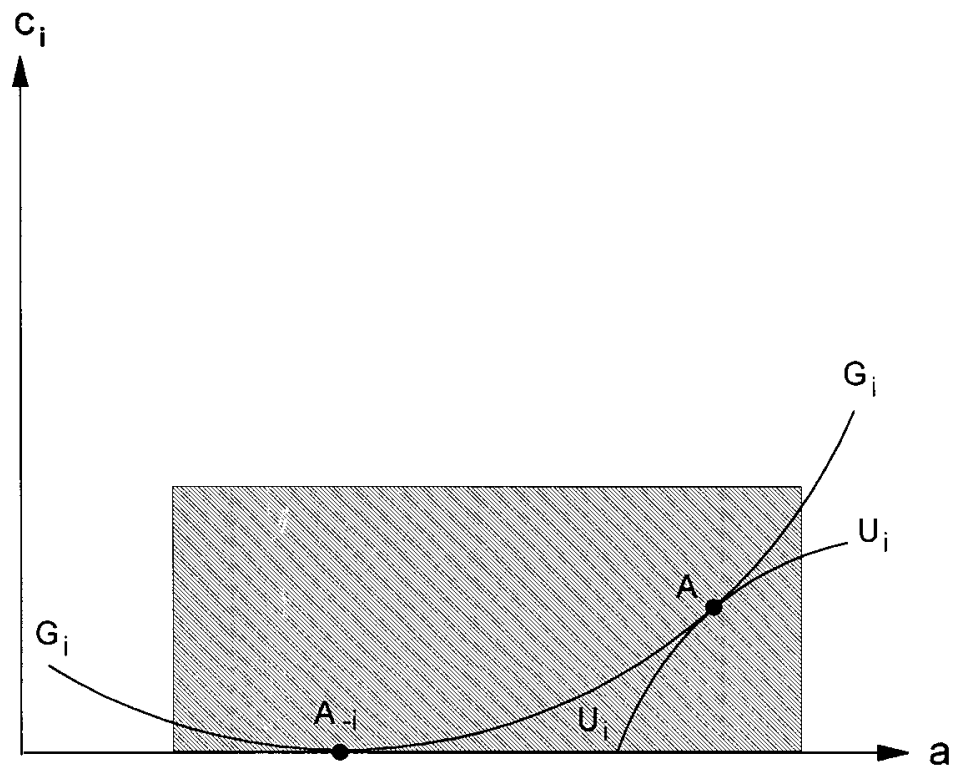

FIG. 1

The intuition behind our result can be appreciated with the aid of figure 1. Suppose for the sake of illustration that the action is a scalar. Curve $G_{i} G_{i}$ depicts combinations of the action a (on the horizontal axis) and payments $c_{i}$ by principal $i$ (on the vertical axis) that give the agent a fixed level of utility when the contribution functions of the other principals are given. The particular indifference curve shown in the figure depicts the highest welfare the agent can attain when principal $i$ makes no contribution whatsoever (his payment function coincides with the horizontal axis); the agent then chooses the action associated with the point labeled $A_{-i}$. The shaded rectangle depicts the combinations of feasible actions and feasible payment levels (there is an upper bound on payments, payments must be nonnegative, and the action is bounded below and above). When the agent's option to take action $A_{-i}$ is considered, the best the principal $i$ can do is to design a payment schedule that induces the agent to choose a point in the shaded area that lies above or on the indifference curve $G_{i} G_{i}$. Suppose that the principal's welfare is increasing in the action. Then his indifference curves are upward sloping. In the event, he will choose the feasible point on the rising portion of $G_{i} G_{i}$ that gives him the highest welfare level, namely the tangency point $A$ between his indifference curve $U_{i} U_{i}$ and $G_{i} G_{i}$. It 
is easy to see from the figure how the principal can construct a payment schedule that induces the agent to choose point $A$. For example, he might offer a schedule that coincides with the horizontal axis until some point to the right of $A_{-i}$ and then rises to a tangency with $G_{i} G_{i}$ at $A$ without ever crossing that curve.

Corollary to proposition 1. Let $\left(\mathbf{C}^{\circ}, \mathbf{a}^{\circ}\right)$ be an equilibrium. Then, for each $i \in L$,

$$
G\left[\mathbf{a}^{\circ}, \mathbf{C}^{\circ}\left(\mathbf{a}^{\circ}\right)\right]=\sup _{\mathbf{a} \in \mathscr{A}} G\left[\mathbf{a},\left(\left\{C_{j}^{\circ}(\mathbf{a})\right\}_{j \neq i}, 0\right)\right] .
$$

Explanation. This says that the utility level of the agent in equilibrium is the same as what he would get if any one of the principals were to contribute zero whereas all others maintained their equilibrium payment functions, and the agent then chose his optimum action in response to this deviation. The intuition is implicit in our discussion of condition $c$ of the proposition. Each principal must ensure that the agent gets a utility equal to his outside opportunity; it is not in the principal's interest to give the agent any more.

\section{B. Truthful Equilibria}

The model above can have multiple subgame perfect Nash equilibria, some of which can be inefficient. As in Bernheim and Whinston (1986), we now develop a refinement that selects equilibria that implement Pareto-efficient actions (the concept of Pareto efficiency is of course constrained by the set of available actions).

We consider equilibria that can arise when each principal offers the agent a payment function that is truthful. A truthful payment function for principal $i$ rewards the agent for every change in the action exactly the amount of change in the principal's welfare, provided that the payment both before and after the change is strictly positive. In other words, the shape of the payment schedule mirrors the shape of the principal's indifference surface. Then the principal gets the same utility for all actions a that induce positive payments $C_{i}(\mathbf{a})>0$; the payment is just the compensating variation. We show that the common agency game has an equilibrium in which all the principals follow truthful strategies and that such an equilibrium is Pareto-efficient. We call such an equilibrium a truthful equilibrium.

Focus on truthful equilibria may seem restrictive but can be justified in several ways. First, for any set of feasible strategies of the $L-1$ principals other than $i$, the set of best-response strategies for principal $i$ contains a truthful payment function. Thus each principal bears essentially no cost from playing a truthful strategy, no mat- 
ter what he expects from the other players. Then the result that an equilibrium in truthful strategies implements a Pareto-efficient action may make such strategies focal for the group of principals. Second, since the setting has no incomplete information, the players have "nothing to hide" and truthful strategies provide a simple device to achieve efficiency without any player conceding his right to grab as much as he can for himself.

Notice too that we do not restrict the space of feasible payment functions to truthful ones at the outset; in a truthful equilibrium, each principal's truthful strategy is a best response to his rivals even when the space of feasible payment functions is the larger one of assumption 1. Thus we have an equilibrium in the full sense, where the strategies happen to be truthful.

We now proceed to formalize the idea and the results.

Definition 3. A payment function $C_{i}^{T}\left(\mathbf{a}, u_{i}^{*}\right)$ for principal $i$ is truthful relative to the constant $u_{i}^{*}$ if

$$
C_{i}^{T}\left(\mathbf{a}, u_{i}^{*}\right) \equiv \min \left\{\bar{C}_{i}(\mathbf{a}), \max \left[0, \varphi_{i}\left(\mathbf{a}, u_{i}^{*}\right)\right]\right\} \quad \text { for all } \mathbf{a} \in \mathscr{A},
$$

where $\varphi_{i}$ is implicitly defined by $U^{i}\left[\mathbf{a}, \varphi_{i}\left(\mathbf{a}, u_{i}^{*}\right)\right]=u_{i}^{*}$ for all $\mathbf{a} \in \mathscr{A}$, and $\overline{C_{i}}(\mathbf{a})=\sup \left\{C_{i}(\mathbf{a}) \mid C_{i} \in \mathscr{C}_{i}\right\}$ for all $\mathbf{a} \in \mathscr{A}$.

Explanation. The definition of $\varphi_{i}$ is the basic concept of the compensating variation. Equation (3) merely serves to ensure that the truthful payment function also satisfies the upper and lower bounds on feasible payments. Note that a competition in truthful strategies boils down to noncooperative choices of the constants $\left\{u_{j}^{*}\right\}_{j \in L}$, which determine the equilibrium payoffs of the principals.

Proposition 2. The best-response set of principal $i$ to payment functions $\left\{C_{j}^{\circ}(\mathbf{a})\right\}_{j \in L, j \neq i}$ of the other principals contains a truthful payment function.

Explanation. The result can be illustrated in the aforementioned figure 1 . The principals other than $i$ induce in the agent the indifference curve $G_{i} G_{i}$ with their payment offers. These offers might be truthful or not. In any event, the best-response set for principal $i$ includes all payment functions that induce the action and contribution associated with point $A$. A truthful strategy in this set is the payment function that coincides with the horizontal axis from the origin until its intersection with $U_{i} U_{i}$ and coincides with $U_{i} U_{i}$ thereafter.

Definition 4. A truthful equilibrium is an equilibrium in which all payment functions are truthful relative to the equilibrium welfare levels.

Proposition 3. Let $\left(\left\{C_{i}^{T}\right\}_{i \in L}, \mathbf{a}^{\circ}\right)$ be a truthful equilibrium in which $u_{i}^{\circ}$ is the equilibrium utility level of principal $i$, for all $i \in L$. 
Then $\left(\left\{u_{i}^{\circ}\right\}_{i \in L}, \mathbf{a}^{\circ}\right)$ is characterized by $(a) \mathbf{a}^{\circ}=\operatorname{argmax}_{\mathbf{a} \in \mathscr{A}} G[\mathbf{a}$, $\left.\left\{C_{i}^{T}\left(\mathbf{a}, u_{i}^{\circ}\right)\right\}_{i \in L}\right]$ and $(b)$ for every $i \in L$,

$$
G\left[\mathbf{a}^{\circ},\left\{C_{i}^{T}\left(\mathbf{a}^{\circ}, u_{i}^{\circ}\right)\right\}_{i \in L}\right]=\max _{\mathbf{a} \in \mathscr{A}} G\left[\mathbf{a},\left(\left\{C_{j}^{T}\left(\mathbf{a}, u_{i}^{\circ}\right)\right\}_{j \neq i}, 0\right)\right] .
$$

Explanation. This is just a restatement of the corollary to proposition 1, for the case of truthful equilibria, and the explanation given above applies. The added advantage lies in actual use. If we tried to use that corollary to determine equilibria, we would have to solve the conditions simultaneously for all the payment functions, which is a complicated fixed-point problem and has a large multiplicity of solutions. The corresponding set of equations in proposition 3 involves the equilibrium utility numbers; therefore, they constitute a simpler simultaneous equation problem with solutions that are in general locally determinate and in applications often unique. We shall consider one such application in the next section.

Now we establish that an equilibrium in truthful strategies implements an efficient action.

Proposition 4. Let a policy vector $\mathbf{a}^{\circ}$ and a vector of payment functions $\mathbf{C}^{\circ}$ that are truthful with respect to the utility levels $u_{i}^{\circ}=$ $U^{i}\left(\mathbf{a}^{\circ}, C_{i}^{\circ}\left(\mathbf{a}^{\circ}\right)\right)$ constitute a truthful equilibrium. Then there do not exist an action $\mathbf{a}^{*}$ and a payment vector $\mathbf{c}^{*}$ such that the following conditions hold: (i) feasibility: $\mathbf{a}^{*} \in \mathscr{A}$; $0 \leq c_{i}^{*} \leq \bar{C}_{i}\left(\mathbf{a}^{*}\right)$ for all $i \in$ $L$; and (ii) Pareto superiority:

$$
\begin{aligned}
G\left(\mathbf{a}^{*}, \mathbf{c}^{*}\right) & \geq G\left[\mathbf{a}^{\circ}, \mathbf{C}^{\circ}\left(\mathbf{a}^{\circ}\right)\right], \\
U^{i}\left(\mathbf{a}^{*}, c_{i}^{*}\right) & \geq U^{i}\left[\mathbf{a}^{\circ}, C_{i}^{\circ}\left(\mathbf{a}^{\circ}\right)\right] \quad \text { for all } i \in L,
\end{aligned}
$$

with at least one strict inequality.

Explanation. Suppose that such an action $\mathbf{a}^{*}$ and payment vector $\mathbf{c}^{*}$ did exist. Since principal $i$ must be at least as well off with $\mathbf{a}^{*}$ and $c_{i}^{*}$ as in the equilibrium and since his equilibrium payment schedule is truthful, $c_{i}^{*}$ can be no greater than the payment elicited by the action $\mathbf{a}^{*}$ in the equilibrium schedule; that is, $c_{i}^{*} \leq C_{i}^{T}\left(\mathbf{a}^{*}, u_{i}^{\circ}\right)$. Therefore, the agent, who has a positive marginal utility of money, cannot strictly prefer $\mathbf{a}^{*}$ and $\mathbf{c}^{*}$ to the equilibrium values, because the combination of $\mathbf{a}^{*}$ and $\left\{C_{i}^{T}\left(\mathbf{a}^{*}, u_{i}^{\circ}\right)\right\}_{i \in L}$ was available to him and yet he chose $\mathbf{a}^{\circ}$ and $\mathbf{C}^{\circ}\left(\mathbf{a}^{\circ}\right)$. It follows that it must be some principal $i$ who strictly prefers $\mathbf{a}^{*}$ and $c_{i}^{*}$ to the equilibrium action and his equilibrium payment. But then this principal has not obeyed requirement $c$ of proposition 1: he should have asked the agent to choose $\mathbf{a}^{*}$ by offering $c_{i}^{*}$. The agent would be happy to do this because he would also get the truthful contributions $C_{j}^{T}\left(\mathbf{a}^{*}, u_{j}^{\circ}\right)$, which are greater 
than or equal to $c_{j}^{*}$ by the argument above, from all the other principals $j$. It follows that no such $\left(\mathbf{a}^{*}, \mathbf{c}^{*}\right)$ exists.

\section{Quasi-Linear Preferences}

The equilibrium above can be pinned down further when all players' preferences are linear in the payments. Specifically, the action is independent of the distribution in this case.

Corollary 1 TO PROPOSITION 4. Let the preference functions $\left(\left\{U^{i}\right\}_{i \in L}, G\right)$ have the quasi-linear form

$$
U^{i}\left(\mathbf{a}, c_{i}\right)=\omega^{i}(\mathbf{a})-\kappa_{i} c_{i} \quad \text { for all } i \in L
$$

and

$$
G(\mathbf{a}, \mathbf{c})=\Gamma(\mathbf{a})+\gamma \sum_{i \in L} c_{i} .
$$

Consider a truthful equilibrium in which the action is $\mathbf{a}^{\circ}$ and all payments are in the interior: $0<C_{i}^{\circ}\left(\mathbf{a}^{\circ}\right)<\bar{C}_{i}\left(\mathbf{a}^{\circ}\right)$. Then

$$
\mathbf{a}^{\circ}=\underset{\mathbf{a} \in \mathscr{A}}{\operatorname{argmax}} \frac{\Gamma(\mathbf{a})}{\gamma}+\sum_{i \in L} \frac{\omega_{i}(\mathbf{a})}{\kappa_{i}} .
$$

Explanation. With quasi-linear preferences, the equilibrium action maximizes a weighted sum of gross welfare levels of the principals and the agent. This result has been useful in applications to political economy, such as in Grossman and Helpman (1994). There, the agent is a government that sets a vector of tariff policies, and the principals are interest groups representing owners of sector-specific factors of production. The government's objective is assumed to be linear in the aggregate welfare of voters and the total of campaign contributions collected from special interests. The corollary predicts a structure of protection that maximizes a simple weighted sum of the welfare of voters and interest group members.

\section{Application to Government Policy Making}

As we noted in the Introduction, common agency arises frequently in the political processes that generate economic policies. The policy makers often can be viewed as an agent and some or all of their constituents as principals. Principals can "lobby" the policy makers by promising payments in return for policies, within some prescribed limits on available policies and feasible gifts. The payments may take the form of illicit bribes or, more typically, implicit (and therefore legal) offers of campaign support. In such settings, it may 
be natural to think of the government as having an objective function with social welfare and the total of contribution receipts as arguments. The government might care about social welfare for ethical reasons, or it may want to provide a high standard of living to enhance its reelection prospects, to keep the populace sufficiently happy to prevent riots, and so forth. Contributions likewise might enter the government's objective because they affect its reelection chances, or merely as utility of the governing elites' private consumption. Accordingly, we suppose $G(\mathbf{a}, \mathbf{c})=g(\mathbf{u}, c)$, where $\mathbf{u}$ is the vector of all the individuals' utilities, and $c=\sum_{i=1}^{n} c_{i}$ is the aggregate contribution received by the government. We assume that $g$ is strictly increasing and strictly quasi-concave in all its arguments. ${ }^{4}$

Let $L$ be the set of individuals who can lobby the government for special favors. We leave $L$ exogenous: some individuals may have personal connections to the politicians, or some groups of individuals may be able to solve the free-rider problem of collective political action while others cannot. ${ }^{5}$ Then $C_{i}(\mathbf{a}) \equiv 0$ for $i \notin L$. For $i \in L$, the upper limit on feasible contributions, $\bar{C}_{i}(\mathbf{a})$, is implicitly defined by $U^{i}\left[\mathbf{a}, \bar{C}_{i}(\mathbf{a})\right]=\underline{u}_{i}$, where $\underline{u}_{i}$ is the lowest or subsistence utility level for individual $i$.

Proposition 4 has strong implications for the outcome of this lobbying game.

Corollary 2 to proposition 4. Let the agent's preferences be given by $G(\mathbf{a}, \mathbf{c})=g(\mathbf{u}, c)$, where $c=\sum_{i=1}^{n} c_{i}$. Let a set $L \subset\{1,2, \ldots, n\}$ of individuals offer payment schedules $\left\{C_{i}(\mathbf{a})\right\}_{i \in L}$, whereas $C_{i}(\mathbf{a}) \equiv$ 0 for $i \notin L$. Finally, let a policy vector $\mathbf{a}^{\circ}$ and a vector of payment functions $\mathbf{C}^{\circ}$ that are truthful with respect to the utility levels $u_{i}^{\circ}=$ $u_{i}\left[\mathbf{a}^{\circ}, C_{i}^{\circ}\left(\mathbf{a}^{\circ}\right)\right]$ for $i \in L$ constitute a truthful equilibrium in which $u_{i}^{\circ}=u_{i}\left(\mathbf{a}^{\circ}, 0\right)$ for $i \notin L$. Then there exists no other policy vector $\mathbf{a}^{\prime}$ $\in \mathscr{A}$ such that $u_{i}\left(\mathbf{a}^{\prime}, c_{i}^{\circ}\right) \geq u_{i}^{\circ}$ for all $i \in\{1,2, \ldots, n\}$, with strict inequality holding for some $i$.

Explanation. The corollary says that, even under the pressure of lobbying from a subset of organized special interests, a government that has some concern for social welfare will make Pareto-efficient choices from the set of feasible policies. With truthful payment schedules, the government has an incentive to collect its tributes

\footnotetext{
${ }^{4}$ A special case frequent in economic models is one in which the individual utilities are channeled through a social welfare function of the Bergson-Samuelson type:

$$
w=W\left[u_{1}\left(\mathbf{a}, c_{1}\right), u_{2}\left(\mathbf{a}, c_{2}\right), \ldots, u_{n}\left(\mathbf{a}, c_{n}\right)\right]
$$

and $G(\mathbf{a}, \mathbf{c})=g(w, c)$. But the more general form $g(\mathbf{u}, c)$ will suffice for our purpose.

${ }^{5}$ In reality, most lobbying is undertaken by such coalitions. If a group of individuals can arrange an optimal internal transfer scheme, it can be regarded as a Samuelsonian aggregated "individual" in our model.
} 
efficiently. If the government's objective weighs positively the wellbeing of all members in society, then efficiency for the government and lobbies translates into Pareto efficiency for the polity as a whole. ${ }^{6}$

It is important to distinguish between efficiency in the sense of the earlier proposition 4 and that of its corollary 2 above. In the former, only the welfare of the active players in the game (the lobbies and the government) is considered. This leaves open the possibility that when there are other individuals in the background but they are not strategic players (principals in the lobbying game), inefficiencies in their welfares can remain. In corollary 2 to proposition 4 , the government's objective function gives some weight to the welfare levels of such individuals, and therefore, for the given level of its receipts from the lobbies, it implements an action that is efficient for all individuals, whether lobbying or not.

The implications of our result can be seen most clearly in a simple and familiar economic application. We consider now a positive analogue to the normative theory of taxes and transfers à la Diamond and Mirrlees (1971). Our analysis extends theirs to situations in which the government cares not only about aggregate welfare but also about the campaign contributions it can amass. ${ }^{7}$

To simplify the exposition, we suppose that the economy is small and open. Let $\mathbf{p}^{w}$ denote the exogenous vector of world prices and $\mathbf{q}$ and $\mathbf{p}$ the price vectors faced by the domestic consumers and producers, respectively. Then $\mathbf{q}-\mathbf{p}^{w}$ is the implied vector of consumer tax rates (negative components are subsidies) and $\mathbf{p}-\mathbf{p}^{w}$ the implied vector of producer subsidy rates (negative components are taxes). The government's tax and subsidy policies are therefore equivalent to choosing $\mathbf{q}$ and $\mathbf{p}$. The government can also make lump-sum transfers or levy lump-sum taxes on any or all individuals; let $\mathbf{t}$, with components $t_{i}$, denote the vector of such transfers (negative components are taxes). We leave out any other government activities for simplicity.

There are several firms labeled $f \in M$ with profit functions $\psi^{f}(\mathbf{p})$. Individual $i$ owns an exogenous share $\omega_{i f}$ of firm $f$ and therefore gets profit income $\pi^{i}(\mathbf{p})=\sum_{f \in M} \omega_{i} \psi^{f}(\mathbf{p})$. Let $c_{i}$ denote the lobbying payment of individual $i$ to the government, for $i \in L$. Set $c_{i} \equiv 0$ for $i \notin L$. Then individual $i$ 's income is $I_{i} \equiv \pi^{i}(\mathbf{p})+t_{i}-c_{i}$, and we can

\footnotetext{
${ }^{6}$ It also follows from proposition 4 that there exists no vector of policies a and contributions $\mathbf{c}$ that would leave the government and all lobbyers and nonlobbyers at least as well off as in the political equilibrium, and some individual or the government strictly better off. In this sense, the political outcome achieves second-best efficiency given the set of available policy instruments.

${ }^{7}$ The model is laid out and analyzed in greater detail in our working paper (Dixit et al. 1996).
} 
write the resulting indirect utility function as $u_{i}=V^{i}\left(\mathbf{q}, I_{i}\right)$. We assume that each $V^{i}$ is strictly increasing and strictly concave in $I_{i}$. These lump-sum incomes $I_{i}$ do not have to be nonnegative because individuals have additional incomes from sales of factor services. There is some other lower bound to the $I_{i}{ }^{8}$ However, we assume an "Inada condition" that the marginal utility of income $V_{I}^{i}\left(\mathbf{q}, I_{i}\right)$ goes to infinity as this lower bound is approached; therefore, the bound is never hit and we ignore it in what follows.

We should emphasize that the payments made by the lobbies do not enter into the government's tax and transfer budget. This budget reflects the "public" or policy part of the government's activities. The lobbies' payments go into a separate "private" or political kitty. They might be used by the governing party for its reelection campaign or by a governing dictator for his own consumption.

We can now regard the government as choosing $\mathbf{a}=(\mathbf{q}, \mathbf{p}, \mathbf{t})$ to maximize $g(\mathbf{u}, c)$ subject to the two (public and political) budget constraints. This puts the problem in the framework of our model of government policy making. Corollary 2 to proposition 4 tells us that the equilibrium action achieves a Pareto-efficient outcome in an auxiliary problem in which the lobbies' payments are held fixed at their equilibrium levels. In the auxiliary problem, the government's choice is the standard normative optimal tax and transfer problem, where we know that if lump-sum transfers are available, distorting commodity taxes and subsidies will not be used. Therefore, we have shown that the political equilibrium will also preserve $\mathbf{q}=\mathbf{p}=\mathbf{p}^{w}$ and use only the lump-sum transfers $\mathbf{t}$ for the two purposes of eliciting contributions from the lobbies and of meeting the government's concern for the welfare of the nonlobbying individuals.

Before the reader forms the belief that we have established the universal efficiency of the political process of tax policy, we should warn that the story is not yet complete. It remains to examine the distribution of gains between the lobbies and the government in the political equilibrium; that analysis may cast doubt on the efficient equilibrium as a description of political reality.

Condition $b$ of proposition 3 helps us to calculate the individuals' utility levels $u^{\circ}$ and the government's receipts from the lobbies. The condition says that the government's utility in equilibrium should equal what it would get by responding optimally to the equilibrium payment schedules of all the lobbies except one that pays nothing. The equations this generates are to be solved simultaneously.

\footnotetext{
${ }^{8}$ This limit may depend on the price vector $\mathbf{q}$ and is defined by the condition $V^{i}\left(\mathbf{q}, I_{i}\right)=\underline{u}_{i}$, where $\underline{u}_{i}$ is the lowest or subsistence utility level.
} 
Using our efficiency result, we set $\mathbf{p}=\mathbf{q}=\mathbf{p}^{w}$ and omit these arguments from the various functions. Let $U^{i}\left(I_{i}\right)=V^{i}\left(\mathbf{p}^{w}, I_{i}\right)$. Define $\pi_{i}=\pi^{i}\left(\mathbf{p}^{w}\right)$, and think of them as the individuals' endowments. Finally, let $\pi \equiv \sum_{i \in N} \pi_{i}$ for the total endowment in the economy, and assume that it is positive. Then the nonlobbyers' incomes are $\pi_{i}+$ $t_{i}$, and the lobbies' truthful contribution schedules are $C_{i}\left(t_{i}, u_{i}^{\circ}\right)=$ $\max \left[\pi_{i}+t_{i}-E^{i}\left(u_{i}^{\circ}\right), 0\right]$, where the expenditure functions $E^{i}$ are inverses to the utility functions $U^{i}$.

We shall find that when there are two or more lobbies, any one of them has no economic power in its agency relationship with the government. Indeed, the effect is exactly as though the government could rob the official budget directly for its political kitty, without having to rely on any lobbies or their contributions at all. If the government is given this much power, the only reason it would give anything to any group is that it cares directly about social welfare as well as about its own consumption. In other words, such a "partially benevolent dictator" government would solve the following maximization problem.

Problem A. $\max _{\mathbf{I}, c} g\left(U^{1}\left(I_{1}\right), \ldots, U^{n}\left(I_{n}\right), c\right)$ subject to $c \geq 0$ and $\sum_{i \in N} I_{i}+c \leq \pi$.

Given our assumptions, namely that all the functions $U^{i}\left(I_{i}\right)$ are strictly increasing and strictly concave and that the function $g(\mathbf{u}, c)$ is strictly increasing and quasi-concave, this problem has a unique solution. Because we have assumed the Inada condition that the marginal utility of each individual goes to infinity as the utility goes to its subsistence level, we do not need to impose any lower bounds on the $I_{i}$.

We state the equivalence between the political equilibrium and the choice of this partially benevolent dictator in the following result.

Proposition 5. Assume that the set $L$ has at least two members. Then the unique solution of problem A yields a truthful equilibrium. Moreover, if all the functions $U^{i}(\cdot)$ and $g(\cdot)$ are differentiable, then any truthful equilibrium solves problem A (and is therefore unique).

Explanation. The government's power in the agency relationship derives from the fact that if any one lobby were to withdraw from its activity, the government would get exactly the same total contribution from its dealings with the others. It would simply cut the transfer to the deviant lobby by an amount equal to that lobby's contribution and redirect the funds to some other lobbies. Since these others all have truthful payment schedules, the government would receive back the entire amount of the redirected transfers as additional contributions from them. Therefore, all the lobbies are perfect substitutes in the eyes of the government as sources of funding, and so 
no one of them can bring harm to the government by withholding its tribute. The government implicitly wields the credible threat of cutting any one lobby out of the deal at no cost to itself. ${ }^{9}$

An alternative way to think of this is that truthful schedules set up a Bertrand-like competition among the lobbies. In the resulting equilibrium, they outbid each other for every dollar of government transfer, to the point at which everyone is bidding the full dollar.

The lobbies fare no better than they would if they were nonlobbyers but some others were active in lobbying. This is a terrible outcome for the lobbies, and each one could achieve the same result unilaterally by renouncing its lobbying activities. However, such unilateral renunciation by all lobbies would not be an equilibrium because starting from such a position, each one would want to lobby; that is the essence of a prisoners' dilemma!

Note that our result requires that there be at least two lobbies: were one to deviate, the government could find a substitute with which to "work a deal." If there is only one lobby, then were that lobby to deviate, the government could not bestow its transfer on another contributor and get it back dollar for dollar. The best the government could do would be to spread its transfer around to maximize social welfare, which cannot be better or else it would already be doing so in the equilibrium. In short, a single lobby captures all the surplus inherent in its relationship with the government. ${ }^{10}$ But as soon as there are two or more lobbies, each one loses all power and the government captures the entire surplus in the form of contributions.

We can also see that the existence of lump-sum transfers is essential for this argument. If all the available redistributive instruments were distortionary, then to compensate fully for the contributions lost when one lobby deviates, the government must increase the levels of the instruments favoring the other lobbies. This causes greater and greater marginal distortion and so is costly to the government. The extra cost is the power that each potential deviator has in its dealings with the government, and the equivalent variation of this extra distortion equals the amount of surplus the lobby can extract in equilibrium. This is illustrated by Grossman and Helpman (1994) for tariffs and by Dixit (1996) for production subsidies.

\footnotetext{
${ }^{9}$ This is not an explicit threat in the game-theoretic sense because the government makes no prior move to set up its contingent response; the right response happens to be its ex post optimal action.

${ }^{10}$ The single lobby derives its power from its assumed ability to make take-it-orleave-it offers. If the lobby and the government instead were to negotiate over the size of the tribute, then each would share in the surplus from their bilateral relationship.
} 
Thus, while our result that more efficient instruments are used in equilibrium when they are available supports the argument of Becker (1983), the distributional implications of the two models are totally different. In Becker's paper (pp. 385-86), the replacement of a less efficient by a more efficient instrument generally allows the lobbies to achieve the same or better results using less resources in exerting political pressure. Therefore, they unanimously favor the more efficient instrument. In our model, the government's choice of action achieves efficiency because the government attaches some weight to social welfare. The lobbying groups actually fare poorly in their competition when more efficient instruments are used. Each of these groups gets only the utility it would get if it were not lobbying, but some other group or groups were lobbying, which is even worse than what it gets if no one lobbies at all.

Finally, compare two alternative policy regimes, one with nondistorting lump-sum taxes or transfers and the other with distorting transaction-based taxes or subsidies. The political equilibrium in the former has more total ouput, which should translate into higher market incomes for everyone. But in this regime, the government gets all the surplus that can be extracted by taxing the unorganized groups in society. In the other regime, all groups generally get lower market incomes, but the organized interests capture some of the surplus from their political activity. It is conceivable that on balance the organized interests fare better in the latter regime, so they would unanimously endorse a constitutional rule restricting the government to inefficient redistributive policies. Thus our model suggests a new way by which distorting policies might emerge as a political equilibrium. ${ }^{11}$ This seems an interesting question for future research.

\section{References}

Becker, Gary S. “A Theory of Competition among Pressure Groups for Political Influence.” Q.J.E. 98 (August 1983): 371-400.

Bernheim, B. Douglas, and Whinston, Michael D. "Menu Auctions, Resource Allocation, and Economic Influence." Q.J.E. 101 (February 1986): $1-31$.

Coate, Stephen, and Morris, Stephen. "'On the Form of Transfers to Special Interests." J.P.E. 103 (December 1995): 1210-35.

Diamond, Peter A., and Mirrlees, James A. "Optimal Taxation and Public Production.”' 2 pts. A.E.R. 61 (March 1971): 8-27; (June 1971): 261-78.

${ }^{11}$ Hammond (1979) argues that individualized lump-sum transfers are infeasible for informational reasons. See also Coate and Morris (1995) for an informational reason and Dixit and Londregan (1995) for a commitment reason why the political process uses inefficient instruments. 
Dixit, Avinash K. 'Special-Interest Lobbying and Endogenous Commodity Taxation." Eastern Econ. J. 22 (Fall 1996): 375-88.

Dixit, Avinash K.; Grossman, Gene M.; and Helpman, Elhanan. "Common Agency and Coordination: General Theory and Application to Tax Policy." Discussion Paper no. 1436. London: Centre Econ. Policy Res., 1996.

Dixit, Avinash K., and Londregan, John B. "Redistributive Politics and Economic Efficiency." American Polit. Sci. Rev. 89 (December 1995): 856-66.

Grossman, Gene M., and Helpman, Elhanan. "Protection for Sale." A.E.R. 84 (September 1994): 833-50.

Hammond, Peter J. "Straightforward Individual Incentive Compatibility in Large Economies.”' Rev. Econ. Studies 46 (April 1979): 263-82. 